\title{
Vitamin D Receptor Polymorphisms Predispose to Primary Biliary Cirrhosis and Severity of the Disease in Polish Population
}

\author{
Agnieszka Kempińska-Podhorecka, ${ }^{1}$ Ewa Wunsch, ${ }^{2}$ Tomasz Jarowicz, ${ }^{2}$ \\ Joanna Raszeja-Wyszomirska, ${ }^{2}$ Beata Loniewska, ${ }^{3}$ Mariusz Kaczmarczyk, ${ }^{4}$ \\ Małgorzata Milkiewicz, ${ }^{1}$ and Piotr Milkiewicz ${ }^{2}$ \\ ${ }^{1}$ Medical Biology Laboratory, Pomeranian Medical University, Szczecin, Poland \\ ${ }^{2}$ Liver Unit and Liver Research Laboratories, Pomeranian Medical University, Szczecin, Poland \\ ${ }^{3}$ Department of Neonatal Diseases, Pomeranian Medical University, Szczecin, Poland \\ ${ }^{4}$ Department of Clinical and Molecular Biochemistry, Pomeranian Medical University, Szczecin, Poland
}

Correspondence should be addressed to Piotr Milkiewicz, milkiewp@sci.pum.edu.pl

Received 2 January 2012; Accepted 6 February 2012

Academic Editor: P. Gionchetti

Copyright ( 2012 Agnieszka Kempińska-Podhorecka et al. This is an open access article distributed under the Creative Commons Attribution License, which permits unrestricted use, distribution, and reproduction in any medium, provided the original work is properly cited.

\begin{abstract}
Primary biliary cirrhosis $(\mathrm{PBC})$ is a chronic cholestatic liver condition characterized by the immune-mediated damage of the intrahepatic bile ducts. Polymorphisms of vitamin D receptor (VDR) are considered to contribute to its pathogenesis however their incidence varies in different populations and their potential association with the course of the disease has not been studied. In this paper we investigated the incidence and correlation of three VDR polymorphisms (BsmI, ApaI or TaqI) with various clinical, biochemical, and serological factors in a homogenous group of 143 Caucasian patients with PBC. Control group comprises 306 DNA samples from umbilical cord blood of healthy newborn children. When compared to controls, we observed a significant dominance of the $b$ allele in the BsmI $(\mathrm{OR}=1.69$ [1.27-2.24]; $P=0.0003)$ and $t$ allele in the TaqI $(\mathrm{OR}=0.62[0.47-0.82]$, $P=0.0001)$ in patients with PBC. Moreover the BsmI and TaqI polymorphisms were associated with the presence of advanced fibrosis/liver cirrhosis at the diagnosis of PBC. Pairwise linkage disequilibrium (LD) calculations proved that the analyzed SNPs are within an LD block $\left(100 \%\right.$ of LDs were $\left.D^{\prime}>0.9\right)$. Our study showed, for the first time, that the analyzed polymorphisms of VRD may exert an effect on a natural history of PBC.
\end{abstract}

\section{Introduction}

Primary biliary cirrhosis $(\mathrm{PBC})$ is a chronic cholestatic liver condition [1] which may lead to cirrhosis and liver failure $[2,3]$. The presence of highly specific M2 antimitochondrial antibodies (AMAs) is a serological hallmark of the disease $[4,5]$. PBC affects mainly women in their 5 th and 6 th decade of life and is often associated with other autoimmune conditions. Although etiology of PBC remains to be fully elucidated, genetic factors are known to contribute to its pathogenesis [6]. Previous studies suggested major histocompatibility complex (MHC) class II polymorphisms as showing the strongest, mainly protective, association [7]. Four recent genomewide association studies (GWASs) which included (i) North American, (ii) Italian (iii) mostly North American, and (iv) British cohorts, respectively, pointed at a number of genes potentially involved in the pathogenesis of $\mathrm{PBC}$ and emphasized the role of IL-12 pathway [8-11].

A fat-soluble secosteroid hormone 1,25-dihydroxyvitamin D3 $\left(1,25(\mathrm{OH})_{2} \mathrm{D}_{3}\right)$, apart from its central role in calcium and bone metabolism, possesses immunomodulatory properties and represents an important component of the immune system homeostasis [12]. Many observations suggest that $1,25(\mathrm{OH})_{2} \mathrm{D}_{3}$ can influence the risk of various autoimmune conditions, such as rheumatoid arthritis, type 1 diabetes, multiple sclerosis, systemic sclerosis, or inflammatory bowel disease [13-21].

$1,25(\mathrm{OH})_{2} \mathrm{D}_{3}$ exerts the biological effects through its own nuclear hormone receptor, the vitamin $\mathrm{D}$ receptor (VDR), which belongs to the family of transacting transcriptional regulatory factors [22]. VDR is expressed in most tissues and regulates the expression of as many as 500 target genes in 
TABle 1: Demographic data of analyzed subjects.

\begin{tabular}{lcc}
\hline Feature & PBC $(n=143)$ & Control group $(n=306)$ \\
\hline Age (median; range) & $55(28-90)$ & NA \\
Gender (M/F) & $20 / 123$ & NA \\
Biopsy-confirmed cirrhosis (Y/N) & $38 / 64$ & NA \\
AMA (pos/neg) & $118 / 25$ & NA \\
ALT (median; range) IU/l $(N-3-30)$ & $47(10-987)$ & NA \\
AP (median; range), IU/l $(N-40-120)$ & $286(37-1344)$ & NA \\
GGT (median; range), IU/l $(N-3-30)$ & $177(11-1932)$ & NA \\
Bilirubin (median; range), mg/dl $(N-0.2-1.0)$ & $0.9(0.2-45.0)$ & NA \\
Albumin (median; range), g/dl $(N-3.8-4.4)$ & $4.0(2.1-5.8)$ & NA \\
INR (median; range) $(N-0.8-1.2)$ & $1.0(0.8-2.3)$ & NA \\
Cholesterol (median; range $), \mathrm{mg} / \mathrm{dl}(N<200)$ & $217(50-1096)$ & NA \\
Triglycerides (median; range), $\mathrm{mg} / \mathrm{dl}(N<150)$ & $105(47-681)$ & NA \\
\hline
\end{tabular}

the human genome [23]. Recent studies have indicated several polymorphisms in this large gene. Three of them, rs1544410 (BsmI), rs7975232 (ApaI) (both in intron 8), and rs731236 (TaqI; in exon 9), discovered at the $3^{\prime}$ end of the VDR gene, have been analyzed in the past but their effects on VDR function still remain poorly understood [24-26]. Their relationship with $\mathrm{PBC}$ has been suggested in various populations including the Japanese, Italian, Chinese, German, or Hungarian [27-30] but not confirmed with previously mentioned GWAS. There are also very little available data about the relationship between these polymorphisms and clinical, laboratory findings and susceptibility to liver cirrhosis in patients with PBC.

In this study we investigated the prevalence of VDR polymorphisms in a homogenous cohort of well-characterized Polish patients with PBC. We also looked at a potential effect of these polymorphisms on the clinical and laboratory features in analyzed cohort of patients.

\section{Materials and Methods}

2.1. Patients. One hundred and forty-three patients $(20$ males, 123 females; median age at diagnosis 55 years, range 28-90 years) were enrolled in this study. All patients met the criteria for the diagnosis of $\mathrm{PBC}$ recently introduced by EASL Guidelines [31] according to which PBC can be diagnosed if at least 2 out of the following 3 criteria are fulfilled: elevation of alkaline phosphatase, typical liver histology, and AMA seropositivity. In $102(71.3 \%)$ of patients the diagnosis of PBC was confirmed with liver biopsy out of which in 38 $(37.2 \%)$ histology showed liver cirrhosis. In total, forty-eight (33.6\%) patients had histological/clinical/imaging signs typical for liver cirrhosis.

Umbilical cord blood samples from 306 healthy newborn children served as controls. Data of analyzed subjects are summarized in Table 1. Appropriate informed consent was obtained from each patient included in the study. The study protocol was approved by the ethics committee of Pomeranian Medical University and conforms to the ethical guidelines of the 1975 Declaration of Helsinki (6th revision, 2008).
2.2. VDR Genotyping. DNA from peripheral blood mononuclear cells was isolated using the DNeasy Blood \& Tissue Kit (Qiagen). Oligonucleotide primers and TaqMan probes for VDR polymorphisms ( rs7975232, rs15444410, rs731236) were designed and synthesized by Applied Biosystems (Assay ID: C_28977635_19, C_8716062_10, C_2404008_10, resp.). The fluorescence data were analyzed with allelic discrimination 7500 Software v.2.0.2.

2.3. Statistical Analysis. Data are shown as means and standard deviations. All statistical analyses (Chi-Square, odds ratios, confidence intervals) were carried out using StatView software (Carry, NC, US). The genotype and allelic frequencies were compared between patients and controls using Fisher's PLSD test. The analysis of genotype frequency within $\mathrm{PBC}$ patients in regards to the clinical characteristics was performed using Fisher's PLSD test. Linkage disequilibrium (LD) for rs7975232, rs15444410, and rs731236 for PBC patients was analyzed with the software Haploview 4.2. $P$ value $<0.05$ was consider considered to be statistically significant.

\section{Results}

The following two VDR gene polymorphisms in intron 8 (rs1544410-BsmI; rs7975232-ApaI) and one in exon 9 (rs731236 = TaqI) were analyzed. A significant difference in genotype frequency between patients with $\mathrm{PBC}$ and healthy controls at the BsmI and the TaqI polymorphisms but not at the ApaI polymorphism was found. The $X^{2}$ value and the prevalence of each genotype are shown in Table 2. We found a significant association in the frequency of AA $(B B)$ genotype at the $B s m I$ polymorphism between $\mathrm{PBC}$ patients and controls. $\mathrm{AA}(B B)$ genotype was present less frequently among the patients with $\mathrm{PBC}(14.0 \%$ versus $31.1 \%$ in controls; $\left.X^{2}=14,89 ; P=0.0001\right)$. By contrast, at the TaqI polymorphisms the CC $(t t)$ genotype was represented more frequently $\left(30.2 \%\right.$ versus $12.3 \%$ in controls; $X^{2}=26,07$; $P<0,001)$ and correspondingly, the frequency of TT (TT) genotype decreased significantly in patients with $\mathrm{PBC}$ in comparison to the controls ( $16.0 \%$ versus $33.2 \%$ in controls; 
TABLE 2: Distribution of VDR polymorphisms (rs1544410, rs7975232, rs731236) in PBC patients and controls subjects.

\begin{tabular}{|c|c|c|c|c|}
\hline Genotype & $\mathrm{PBC}(\%)(n=143)$ & Controls $(\%)(n=306)$ & $\chi^{2}$ & $P$ \\
\hline \multicolumn{5}{|c|}{ rs1544410 (BsmI) } \\
\hline $\mathrm{AA}(B B)$ & $20(14.0 \%)$ & $95(31.1 \%)$ & 14.89 & 0.0001 \\
\hline $\mathrm{GA}(b B)$ & $75(52.4 \%)$ & $135(44.1 \%)$ & 2.49 & 0.096 \\
\hline $\mathrm{GG}(b b)$ & $48(33.6 \%)$ & $76(24.8 \%)$ & 3.71 & 0.054 \\
\hline \multicolumn{5}{|c|}{ rs7975232 (ApaI) } \\
\hline $\mathrm{TT}(A A)$ & $40(28 \%)$ & $75(24.9 \%)$ & 0.61 & 0.43 \\
\hline GT $(a A)$ & $80(56 \%)$ & $161(53.5 \%)$ & 0.43 & 0.51 \\
\hline GG (aa) & $23(16 \%)$ & $65(21.6 \%)$ & 1.64 & 0.41 \\
\hline \multicolumn{5}{|c|}{ rs731236 (TaqI) } \\
\hline $\mathrm{TT}(T T)$ & $20(16 \%)$ & $100(33.2 \%)$ & 17.39 & $<0.0001$ \\
\hline $\mathrm{TC}(\mathrm{Tt})$ & $77(53.8 \%)$ & $140(54.5 \%)$ & 2.55 & 0.26 \\
\hline $\mathrm{CC}(t t)$ & $46(30.2 \%)$ & $37(12.3 \%)$ & 26.07 & $<0.0001$ \\
\hline
\end{tabular}

TABLE 3: Allele association for VDR in patients with PBC and control subjects.

\begin{tabular}{|c|c|c|c|c|c|}
\hline SNP & Allele & $\mathrm{PBC}(\%)(n=143)$ & Controls $(\%)(n=306)$ & OR $(95 \% \mathrm{CI})$ & $P$ \\
\hline $\begin{array}{l}\text { rs1544410 } \\
\text { (BsmI) }\end{array}$ & $\begin{array}{l}\text { G/A } \\
(b / B)\end{array}$ & $115(40.2 \%) / 171(59.8 \%)$ & $320(53.2 \%) / 282(46.8 \%)$ & $1.69(1.27-2.24)$ & 0.0003 \\
\hline $\begin{array}{l}\text { rs7975232 } \\
(\text { ApaI) }\end{array}$ & $\begin{array}{l}\mathrm{G} / \mathrm{T} \\
(a / A)\end{array}$ & $160(56 \%) / 126(44 \%)$ & $311(51.7 \%) / 291(48.3 \%)$ & $0.84(0.63-1.2)$ & 0.25 \\
\hline $\begin{array}{l}\text { rs731236 } \\
(\text { TaqI) }\end{array}$ & $\begin{array}{c}\mathrm{T} / \mathrm{C} \\
(T / t)\end{array}$ & $117(41 \%) / 169(59 \%)$ & $364(60.5 \%) / 238(39.5 \%)$ & $0.62(0.47-0.82)$ & 0.0001 \\
\hline
\end{tabular}

PBC: primary biliary cirrhosis; OR: odds ratio; CI: confidence interval.

$\left.X^{2}=17,39 ; P<0,001\right)$. We found no difference at the polymorphism.

Additionally, the analysis of frequencies of each allele in the three polymorphic sites demonstrated a significant dominance of the $b$ allele in the BsmI (OR $=1.69$ [1.272.24]; $P=0.0003)$ and $t$ allele in the TaqI $(\mathrm{OR}=0.62[0.47-$ 0.82 ]; $P=0.0001)$ in $\mathrm{PBC}$ patients in comparison to controls (Table 3). Moreover, in patients with PBC, the BsmI and TaqI polymorphisms were associated with the histological features of advanced fibrosis defined as stage III and IV on histology and cirrhosis (stage IV on histology) (Table 4). Both laboratory markers of the disease severity and AMAs failed to have any association to analyzed polymorphisms (Table 4).

Pairwise linkage disequilibrium (LD) calculations confirmed that the analyzed SNPs are within a LD block (100\% of LDs were $D^{\prime}>0.9$ ) (Figure 1).

\section{Discussion}

In this study we have analyzed the association between BsmI, ApaI, and TaqI polymorphisms and the susceptibility for $\mathrm{PBC}$ and severity of the disease in a homogenous group of Polish patients. We have found that BsmI polymorphism occurred significantly more commonly in patients with PBC than in controls. These findings are consistent with the ones by Vogel et al. [32] and Fan et al. [33], whereas other studies have found a protective association of the " $b$ " allele $[27,34]$. Moreover we have shown the high prevalence of
TaqI polymorphism in patients with $\mathrm{PBC}$, what is again in agreement with the observation by Vogel et al. [32]. In our study a strong association with PBC was demonstrated with " $t$ " allele as well as " $t t$ " genotype, but in the study by Vogel "Tt" genotype was predictive for PBC. Additionally, the study from Tanaka et al. indicated the high prevalence of ApaI in PBC [27], but our study did not show such association.

One may say that in the era of genomewide association studies which involve very large cohorts of subjects analyses aimed at looking at selected polymorphisms in smaller groups have lost their significance. In the context of PBC, four GWASs have been performed and included homogenous groups from Northern American, Italian, mostly Northern American, and British patients, respectively. The first one suggested the role of polymorphisms of gene encoding IL-12 alpha and beta chains [8]. Further GWASs have replicated this finding but also identified new loci associated with antigen-presenting cells and CD4 interactions. Most recent British GWAS identified 12 new susceptibility loci [11].

These results clearly show that each new GWAS adds new susceptibility loci identified in analyzed populations. Thus the fact that VDR polymorphisms were not found in already performed GWAS does not definitely preclude their role in the susceptibility to PBC.

In addition, we have looked at the potential correlation between polymorphisms of VDR gene and clinical and laboratory findings in analyzed patients. We noticed that the polymorphisms of BsmI and TaqI could be associated with 
TABLE 4: Clinical and laboratory data depending on analyzed polymorphisms.

(a)

\begin{tabular}{|c|c|c|c|c|c|c|}
\hline \multicolumn{7}{|c|}{ ApaI (rs7975232) } \\
\hline & $\begin{array}{l}\text { AA }(T T) \\
(n=40)\end{array}$ & $\begin{array}{l}\text { aA }(G T) \\
(n=80)\end{array}$ & $\begin{array}{l}\text { aa }(G G) \\
(n=23)\end{array}$ & $\begin{array}{c}P \\
(A A \text { versus } A a)\end{array}$ & $\begin{array}{c}P \\
(\text { aa versus } A a)\end{array}$ & $\begin{array}{c}P \\
\text { (aa versus } A A)\end{array}$ \\
\hline Gender (F/M) & $36 / 4$ & $67 / 13$ & $20 / 3$ & 0.4 & 0.9 & 0.7 \\
\hline Cirrhosis at Lbx (N/Y) & $20 / 8$ & $34 / 21$ & $10 / 9$ & 0.5 & 0.6 & 0.2 \\
\hline $\begin{array}{l}\text { Advanced fibrosis stage III/IV on } \\
\text { histology }(\mathrm{N} / \mathrm{Y})\end{array}$ & $15 / 11$ & $28 / 27$ & $8 / 10$ & 0.6 & 0.3 & 0.5 \\
\hline Age of diagnosis (years) & $55.0 \pm 1.7$ & $55.7 \pm 1.5$ & $58 \pm 2.2$ & 0.8 & 0.4 & 0.3 \\
\hline AST (IU/mL) & $60.0 \pm 7.9$ & $81.5 \pm 14.8$ & $104.5 \pm 40.4$ & 0.4 & 0.4 & 0.2 \\
\hline ALT (IU/mL) & $57.0 \pm 8.0$ & $82.1 \pm 14.4$ & $84.7 \pm 21.4$ & 0.2 & 0.9 & 0.3 \\
\hline $\mathrm{AP}(\mathrm{IU} / \mathrm{mL})$ & $226.9 \pm 31.5$ & $288 \pm 25.9$ & $371.3 \pm 64.5$ & 0.2 & 0.1 & 0.02 \\
\hline GGT (IU/mL) & $195.7 \pm 32.0$ & $279.0 \pm 36.6$ & $280.8 \pm 44.5$ & 0.1 & 0.9 & 0.2 \\
\hline Bilirubin (mg/dL) & $4.0 \pm 1.7$ & $4.2 \pm 0.9$ & $2.3 \pm 0.9$ & 0.9 & 0.3 & 0.4 \\
\hline Albumin (g/dL) & $3.6 \pm 9.7$ & $3.8 \pm 0.1$ & $3.9 \pm 0.1$ & 0.1 & 0.9 & 0.2 \\
\hline INR & $1.1 \pm 0.04$ & $1.1 \pm 0.03$ & $1.1 \pm 0.03$ & 0.1 & 0.1 & 0.9 \\
\hline Cholesterol (mg/dL) & $220.6 \pm 14.3$ & $241.4 \pm 18.5$ & $227.3 \pm 146$ & 0.4 & 0.7 & 0.8 \\
\hline TG (mg/dL) & $142.4 \pm 22.9$ & $120.6 \pm 6.8$ & $125.7 \pm 18$ & 0.2 & 0.8 & 0.5 \\
\hline Sp100 Ab & $34 / 4$ & $62 / 16$ & $17 / 5$ & 0.3 & 0.8 & 0.3 \\
\hline Gp210 Ab & $31 / 7$ & $67 / 11$ & $21 / 1$ & 0.6 & 0.3 & 0.2 \\
\hline $\operatorname{AMA}(\mathrm{Y} / \mathrm{N})$ & $31 / 9$ & $68 / 12$ & $19 / 4$ & 0.3 & 0.7 & 0.7 \\
\hline
\end{tabular}

(b)

\begin{tabular}{|c|c|c|c|c|c|c|}
\hline \multicolumn{7}{|c|}{ BsmI (rs15444410) } \\
\hline & $\begin{array}{l}\mathrm{bb}(\mathrm{GG}) \\
(n=48)\end{array}$ & $\begin{array}{l}\mathrm{bB}(\mathrm{GA}) \\
(n=75)\end{array}$ & $\begin{array}{l}\mathrm{BB}(\mathrm{AA}) \\
(n=20)\end{array}$ & $\begin{array}{c}P \\
(b b \text { versus } B b)\end{array}$ & $\begin{array}{c}P \\
(B B \text { versus } B)\end{array}$ & $\begin{array}{c}P \\
(b b \text { versus } B B)\end{array}$ \\
\hline Gender (F/M) & $40 / 8$ & $66 / 9$ & $17 / 3$ & 0.6 & 0.7 & 0.9 \\
\hline Cirrhosis at Lbx (N/Y) & $17 / 22$ & $38 / 13$ & $9 / 3$ & 0.004 & 0.9 & 0.1 \\
\hline $\begin{array}{l}\text { Advanced fibrosis stage III/IV on } \\
\text { histology (N/Y) }\end{array}$ & $15 / 23$ & $30 / 20$ & $6 / 5$ & 0.1 & 0.7 & 0.5 \\
\hline Age of diagnosis (years) & $57.0 \pm 1.6$ & $54.4 \pm 1.4$ & $59.8 \pm 3.1$ & 0.2 & 0.1 & 0.4 \\
\hline $\operatorname{AST}(\mathrm{IU} / \mathrm{mL})$ & $110.0 \pm 29.2$ & $63.0 \pm 5.6$ & $63.1 \pm 13.3$ & 0.05 & 0.9 & 0.2 \\
\hline ALT (IU/mL) & $91.9 \pm 22.3$ & $68.6 \pm 9.0$ & $62.7 \pm 13.5$ & 0.2 & 0.8 & 0.3 \\
\hline $\mathrm{AP}(\mathrm{IU} / \mathrm{mL})$ & $321.8 \pm 35.3$ & $283.2 \pm 29.3$ & $195.3 \pm 26.4$ & 0.4 & 0.2 & 0.06 \\
\hline GGT (IU/mL) & $312.0 \pm 48.3$ & $240.1 \pm 29.6$ & $170.4 \pm 35.6$ & 0.2 & 0.3 & 0.7 \\
\hline Bilirubin (mg/dL) & $3.3 \pm 1.0$ & $4.4 \pm 1.1$ & $2.8 \pm 2.0$ & 0.5 & 0.5 & 0.8 \\
\hline Albumin (g/dL) & $3.9 \pm 0.1$ & $8.4 \pm 4.6$ & $3.9 \pm 0.2$ & 0.4 & 0.6 & 0.9 \\
\hline INR & $1.1 \pm 0.02$ & $1.1 \pm 0.03$ & $1.1 \pm 0.1$ & 0.2 & 0.4 & 0.9 \\
\hline Cholesterol (mg/dL) & $233.6 \pm 18.6$ & $239.5 \pm 17.1$ & $206.8 \pm 21.2$ & 0.8 & 0.4 & 0.5 \\
\hline $\mathrm{TG}(\mathrm{mg} / \mathrm{dL})$ & $126.2 \pm 9.9$ & $133.9 \pm 13.3$ & $103 \pm 10.4$ & 0.6 & 0.2 & 0.4 \\
\hline Sp100 Ab & $35 / 12$ & $63 / 10$ & $15 / 3$ & 0.1 & 0.7 & 0.5 \\
\hline Gp210 Ab & $41 / 6$ & $62 / 11$ & $16 / 2$ & 0.8 & 0.9 & 0.9 \\
\hline AMA (Y/N) & $40 / 8$ & $63 / 12$ & $15 / 5$ & $>0.9$ & 0.3 & 0.5 \\
\hline \multicolumn{7}{|c|}{ (c) } \\
\hline \multicolumn{7}{|c|}{ TaqI (rs731236) } \\
\hline & $\begin{array}{l}\mathrm{TT}(\mathrm{TT}) \\
(n=20)\end{array}$ & $\begin{array}{l}\mathrm{Tt}(\mathrm{TC}) \\
(n=77)\end{array}$ & $\begin{array}{l}\mathrm{Tt}(\mathrm{CC}) \\
(n=46)\end{array}$ & $\begin{array}{c}P \\
(T T \text { versus } \\
t T) \\
\end{array}$ & $\begin{array}{c}P \\
(t t \text { versus } t T)\end{array}$ & $\begin{array}{c}P \\
(\text { tt versus } T T)\end{array}$ \\
\hline Gender (F/M) & $37 / 9$ & $69 / 8$ & $17 / 3$ & 0.2 & 0.7 & 0.7 \\
\hline
\end{tabular}


(c) Continued.

\begin{tabular}{|c|c|c|c|c|c|c|}
\hline \multicolumn{7}{|c|}{ TaqI (rs731236) } \\
\hline & $\begin{array}{l}\text { TT }(\mathrm{TT}) \\
(n=20)\end{array}$ & $\begin{array}{l}\mathrm{Tt}(\mathrm{TC}) \\
(n=77)\end{array}$ & $\begin{array}{l}\mathrm{Tt}(\mathrm{CC}) \\
(n=46)\end{array}$ & $\begin{array}{c}P \\
\text { (TT versus } \\
t T)\end{array}$ & $\begin{array}{c}P \\
(t t \text { versus } t T)\end{array}$ & $\begin{array}{c}P \\
(\text { tt versus } T T)\end{array}$ \\
\hline Cirrhosis at Lbx (N/Y) & $15 / 9$ & $40 / 13$ & $9 / 3$ & 0.3 & $>0.9$ & 0.7 \\
\hline $\begin{array}{l}\text { Advanced fibrosis Stage III/IV on } \\
\text { histology (N/Y) }\end{array}$ & $13 / 23$ & $32 / 20$ & $6 / 5$ & 0.03 & 0.7 & 0.3 \\
\hline Age of diagnosis (years) & $57 \pm 1.6$ & $54 \pm 1.4$ & $60 \pm 3$ & 0.2 & 0.1 & 0.4 \\
\hline AST (IU/mL) & $114.3 \pm 30.4$ & $61.6 \pm 5.5$ & $63.4 \pm 13.2$ & 0.03 & 0.9 & 0.2 \\
\hline $\operatorname{ALT}(\mathrm{IU} / \mathrm{mL})$ & $94.2 \pm 23.2$ & $67.8 \pm 8.8$ & $63.3 \pm 13.4$ & 0.2 & 0.9 & 0.3 \\
\hline $\mathrm{AP}(\mathrm{IU} / \mathrm{mL})$ & $322.7 \pm .36 .4$ & $283.6 \pm 28.7$ & $195.5 \pm 26.4$ & 0.4 & 0.2 & 0.06 \\
\hline GGT (IU/mL) & $309.3 \pm 50.2$ & $243.1 \pm 29.2$ & $173.4 \pm 35.1$ & 0.2 & 0.4 & 0.09 \\
\hline Bilirubin (mg/dL) & $3.9 \pm 1.1$ & $4.1 \pm 1.0$ & $2.8 \pm 1.9$ & 0.9 & 0.6 & 0.6 \\
\hline Albumin (g/dL) & $3.8 \pm 0.1$ & $8.3 \pm 4.5$ & $3.9 \pm 0.2$ & 0.4 & 0.6 & 0.9 \\
\hline INR & $1.1 \pm 0.03$ & $1.1 \pm 0.03$ & $1.1 \pm 0.1$ & 0.6 & 0.5 & 0.7 \\
\hline Cholesterol (mg/dL) & $234.7 \pm 19.6$ & $239.2 \pm 16.5$ & $204.4 \pm 21.2$ & 0.8 & 0.3 & 0.4 \\
\hline TG (mg/dL) & $125.5 \pm 10.3$ & $133.9 \pm 12.8$ & $103.8 \pm 10.8$ & 0.6 & 0.2 & 0.4 \\
\hline Sp100 Ab & $34 / 11$ & $64 / 11$ & $15 / 3$ & 0.2 & 0.9 & 0.7 \\
\hline Gp210 Ab & $39 / 6$ & $64 / 11$ & $16 / 2$ & 0.9 & 0.9 & 0.9 \\
\hline $\operatorname{AMA}(\mathrm{Y} / \mathrm{N})$ & $40 / 6$ & $62 / 15$ & $16 / 4$ & 0.5 & $>0.9$ & 0.5 \\
\hline
\end{tabular}

Lbx: liver biopsy; AspAT: aspartate aminotransferase; AlAT: alanine aminotransferase; AP: alkaline phosphatase; GGT: gamma-glutamyl transferase; INR: international normalized ratio; TG: triglycerides, AMA: antimitochondrial antibodies.

Vitamin D receptor (VDR/ chr. 12q13.11)

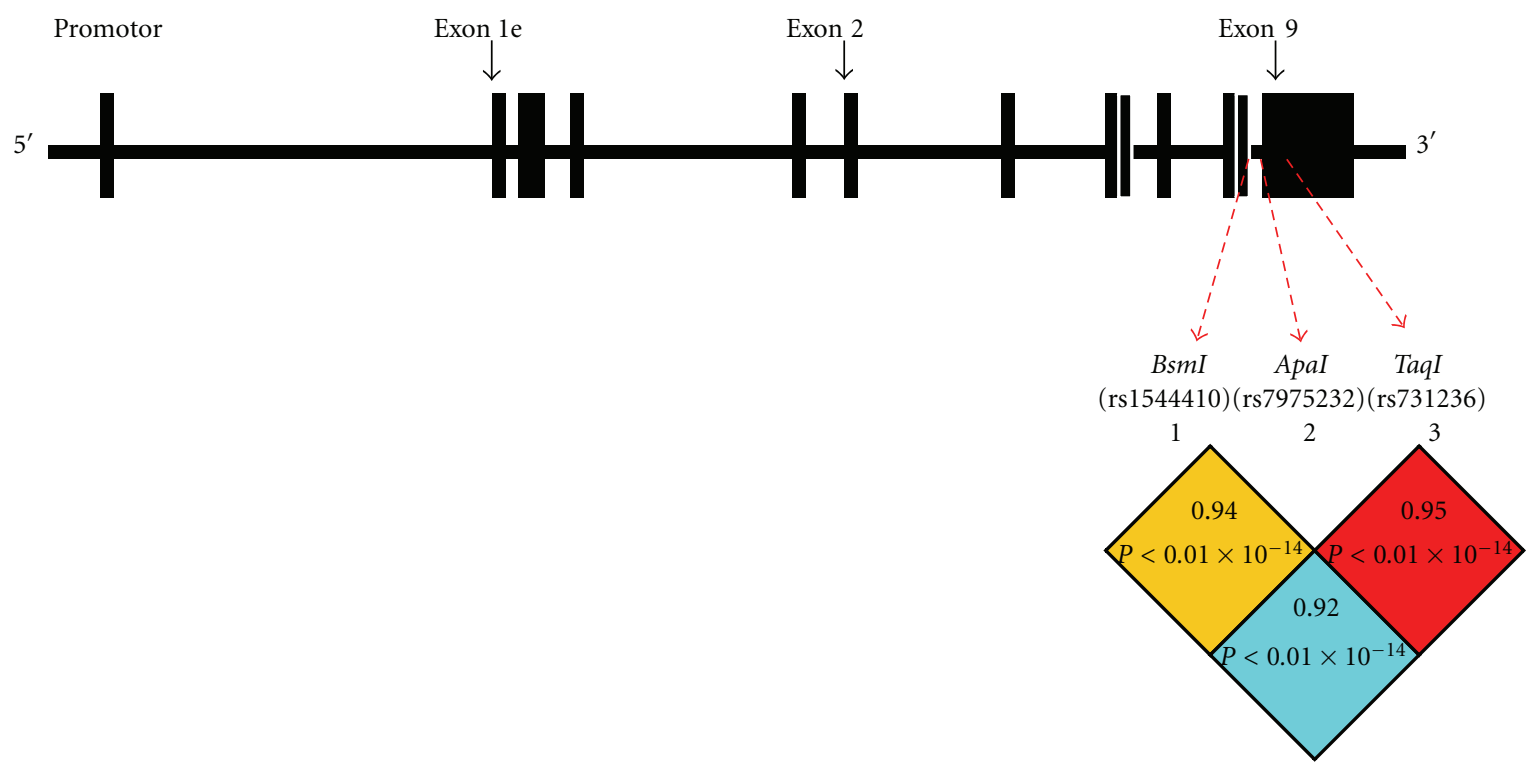

FIgure 1: Pairwise linkage disequilibrium (LD) pattern of the VDR gene SNPs: Rs15444410, rs7975232, rs731236. The location of each examined SNP along the chromosome is indicated. Each square plots the level of D' values between the pair of SNPs.

the susceptibility to liver cirrhosis or advanced fibrosis in these subjects which is a new finding. However we found no significant correlations between the cholestasis or the prevalence of autoantibodies and the presence of analyzed polymorphisms.
Little is known on how the genotype variety of VDR gene is linked to clinical course of the disease as previous studies focused mostly on the prevalences of each polymorphisms in PBC. It is possible that the allelic variety of BsmI and TaqI polymorphisms somehow predisposes to more severe liver 
injury, independently of the biochemical measurements of cholestasis or autoimmune process. Other studies suggested that VDR polymorphisms can contribute to the development of osteoporosis in patients with $\mathrm{PBC}$ [35]; however on the grounds of recent evidence, it is more likely that the cholestasis itself is the main factor of hepatic osteodystrophy, and the indentified polymorphisms play little or no role in the pathogenesis of this complication in patients with $\mathrm{PBC}$ [36].

Interpretation of the significance of polymorphisms in the VDR gene is hindered by the fact that the functional effects of allelic variations are poorly understood. Indeed, VDR polymorphisms are considered to be associated with an increased risk of several autoimmune diseases, but so far no correlation has been identified with functional phenotypes [27]. It can be explained by the fact that the TaqI polymorphism results in a silent mutation in exon 9 and the location of the BsmI and ApaI is intronic, thus probably these polymorphisms are anonymous [37]. Thus it could be speculated that BsmI and TaqI are genetic markers of the presence of other, so far unknown functional sequence variations nearby in the VDR gene which is in linkage disequilibrium with identified alleles [27, 32]. Because the linkage disequilibrium can vary through populations, in different studies the same polymorphisms can be associated with inverse relationships to disease susceptibility. Additionally, the pathogenesis of $\mathrm{PBC}$ is for sure multifactorial, influenced by several environmental and genetic interactions and the analysis of one or few genetic factors in different populations may be insufficient to explain observed variables.

The immunomodulatory properties of $1,25(\mathrm{OH})_{2} \mathrm{D}_{3}$ may be one of possible explanations on how VDR polymorphisms can contribute to the pathogenesis of PBC. $1,25(\mathrm{OH})_{2} \mathrm{D}_{3}$ activates monocytes and macrophages and acts as a positive regulator of the development of Th2 cells and production of anti-inflammatory interleukin (IL)-4 and transforming growth factor $\beta[38,39]$. Moreover, VDR agonists inhibit lymphocyte Th1 cell proliferation and production of a number of proinflammatory cytokines (i.e., IL1, IL-2, IL-6, IL-12, interferon $\gamma$, tumor necrosis factor $\alpha$, and $\beta)[40-42]$. PBC is considered a Th1-mediated liver disease [43]; therefore, reduced activity of $1,25(\mathrm{OH})_{2} \mathrm{D}_{3}$-dependent signaling pathways caused by the VDR polymorphisms might skew the immune response to the Th1 pathway, contributing to the development of PBC [27].

Other mechanism, in which VDR polymorphisms can be involved in the pathogenesis of $\mathrm{PBC}$, is a role of VDR as a receptor for a lithocholic acid (LCA) as well as an endocrine receptor for vitamin D signaling. LCA is a secondary bile acid produced by intestinal bacteria from primary bile acids that may escape reabsorption in the intestine and can accumulate to high levels in the enterohepatic circulation of some subjects [44]. LCA is hepatotoxic and has been considered to be involved in the pathogenesis of cholesterol gallstone disease and colon cancer $[45,46]$. VDR is expressed in biliary epithelial cells [47], where it is considered to act as a sensor for toxic secondary bile acids and to induce their elimination through a xenobiotic metabolism pathway. It can be speculated that VDR polymorphisms may somehow disturb the effective biliary elimination of LCA contributing in this way to the biliary damage and development of PBC. The investigation of VDR-regulated LCA metabolism will be helpful in understanding the potential role of the secondary bile acids in $\mathrm{PBC}$ pathogenesis.

In summary, in this present study we have shown the association of BsmI and TaqI polymorphisms of VDR with the susceptibility to PBC in a cohort of Polish patients. Also we have shown that these patients have an increased risk of liver cirrhosis and advanced fibrosis which is a novel finding of this study. Further studies focused not only on the identification of risk polymorphisms involved in development of PBC but also on the mechanism in which they lead to development and the course of the disease are warranted.

\section{References}

[1] J. Neuberger, "Primary biliary cirrhosis," The Lancet, vol. 350, no. 9081, pp. 875-879, 1997.

[2] M. M. Kaplan and M. E. Gershwin, "Primary biliary cirrhosis," The New England Journal of Medicine, vol. 353, no. 12, pp. 1261-1273, 2005.

[3] R. E. Poupon, K. D. Lindor, A. Parés, O. Chazouillères, R. Poupon, and E. J. Heathcote, "Combined analysis of the effect of treatment with ursodeoxycholic acid on histologic progression in primary biliary cirrhosis," Journal of Hepatology, vol. 39, no. 1, pp. 12-16, 2003.

[4] M. E. Gershwin, I. R. Mackay, A. Sturgess, and R. L. Coppel, "Identification and specificity of a cDNA encoding the $70 \mathrm{KD}$ mitochondrial antigen recognized in primary biliary cirrhosis," Journal of Immunology, vol. 138, no. 10, pp. 3525-3531, 1987.

[5] P. Milkiewicz, H. Buwaneswaran, C. Coltescu, Z. Shums, G. L. Norman, and E. J. Heathcote, "Value of autoantibody analysis in the differential diagnosis of chronic cholestatic liver disease," Clinical Gastroenterology and Hepatology, vol. 7, no. 12, pp. 1355-1360, 2009.

[6] C. Selmi, M. J. Mayo, N. Bach et al., "Primary biliary cirrhosis in monozygotic and dizygotic twins: genetics, epigenetics, and environment," Gastroenterology, vol. 127, no. 2, pp. 485-492, 2004.

[7] P. Invernizzi, C. Selmi, F. Poli et al., "Human leukocyte antigen polymorphisms in Italian primary biliary cirrhosis: a multicenter study of 664 patients and 1992 healthy controls," Hepatology, vol. 48, no. 6, pp. 1906-1912, 2008.

[8] G. M. Hirschfield, X. Liu, C. Xu et al., "Primary biliary cirrhosis associated with HLA, IL12A, and IL12RB2 variants," The New England Journal of Medicine, vol. 360, no. 24, pp. 25442555, 2009.

[9] G. M. Hirschfield, X. Liu, Y. Han et al., "Variants at IRF5TNPO3, 17q12-21 and MMEL1 are associated with primary biliary cirrhosis," Nature Genetics, vol. 42, no. 8, pp. 655-657, 2010.

[10] X. Liu, P. Invernizzi, Y. Lu et al., "Genome-wide meta-analyses identify three loci associated with primary biliary cirrhosis," Nature Genetics, vol. 42, no. 8, pp. 658-660, 2010.

[11] G. F. Mells, J. A. Floyd, K. I. Morley et al., "Genome-wide association study identifies 12 new susceptibility loci for primary biliary cirrhosis," Nature genetics, vol. 43, no. 4, pp. 329-332, 2011.

[12] E. Peelen, S. Knippenberg, A. H. Muris et al., "Effects of vitamin D on the peripheral adaptive immune system: a review," Autoimmunity Reviews, vol. 10, no. 12, pp. 733-743, 2011. 
[13] M. Cutolo, C. Pizzorni, and A. Sulli, "Vitamin D endocrine system involvement in autoimmune rheumatic diseases," $\mathrm{Au}$ toimmunity Reviews, vol. 11, no. 2, pp. 84-87, 2011.

[14] Y. Arnson, H. Amital, N. Agmon-Levin et al., "Serum 25$\mathrm{OH}$ vitamin $\mathrm{D}$ concentrations are linked with various clinical aspects in patients with systemic sclerosis: a retrospective cohort study and review of the literature," Autoimmunity Reviews, vol. 10, no. 8, pp. 490-494, 2011.

[15] C. F. Pelajo, J. M. Lopez-Benitez, and L. C. Miller, "Vitamin $\mathrm{D}$ and autoimmune rheumatologic disorders," Autoimmunity Reviews, vol. 9, no. 7, pp. 507-510, 2010.

[16] H. Amital, Z. Szekanecz, G. Szücs et al., "Serum concentrations of $25-\mathrm{OH}$ vitamin $\mathrm{D}$ in patients with systemic lupus erythematosus (SLE) are inversely related to disease activity: is it time to routinely supplement patients with SLE with vitamin D?" Annals of the Rheumatic Diseases, vol. 69, no. 6, pp. 1155$1157,2010$.

[17] A. Hajas, J. Sandor, L. Csathy et al., "Vitamin D insufficiency in a large MCTD population," Autoimmunity Reviews, vol. 10, no. 6, pp. 317-324, 2011.

[18] J. C. Souberbielle, J. J. Body, J. M. Lappe et al., "Vitamin D and musculoskeletal health, cardiovascular disease, autoimmunity and cancer: recommendations for clinical practice," Autoimmunity Reviews, vol. 9, no. 11, pp. 709-715, 2010.

[19] L. Adorini and G. Penna, "Control of autoimmune diseases by the vitamin D endocrine system," Nature Clinical Practice Rheumatology, vol. 4, no. 8, pp. 404-412, 2008.

[20] M. F. Holick, "Vitamin D deficiency," The New England Journal of Medicine, vol. 357, no. 3, pp. 266-281, 2007.

[21] W. B. Grant, "Epidemiology of disease risks in relation to vitamin D insufficiency," Progress in Biophysics and Molecular Biology, vol. 92, no. 1, pp. 65-79, 2006.

[22] A. W. Norman, "From vitamin D to hormone D: fundamentals of the vitamin D endocrine system essential for good health," American Journal of Clinical Nutrition, vol. 88, no. 2, pp. 491S-499S, 2008.

[23] C. Carlberg, "Current understanding of the function of the nuclear vitamin D receptor in response to its natural and synthetic ligands," Recent Results in Cancer Research, vol. 164, pp. 29-42, 2003.

[24] N. A. Morrison, J. C. Qi, A. Tokita et al., "Prediction of bone density from vitamin D receptor alleles," Nature, vol. 367, no. 6460, pp. 284-287, 1994.

[25] N. A. Morrison, R. Yeoman, P. J. Kelly, and J. A. Eisman, "Contribution of trans-acting factor alleles to normal physiological variability: vitamin D receptor gene polymorphisms and circulating osteocalcin," Proceedings of the National Academy of Sciences of the United States of America, vol. 89, no. 15, pp. 6665-6669, 1992.

[26] J. H. Faraco, N. A. Morrison, A. Baker, J. Shine, and P. M. Frossard, "ApaI dimorphism at the human vitamin D receptor gene locus," Nucleic Acids Research, vol. 17, no. 5, p. 2150, 1989.

[27] A. Tanaka, S. Nezu, S. Uegaki et al., "Vitamin D receptor polymorphisms are associated with increased susceptibility to primary biliary cirrhosis in Japanese and Italian populations," Journal of Hepatology, vol. 50, no. 6, pp. 1202-1209, 2009.

[28] L. Fan, X. Tu, Y. Zhu et al., "Genetic association of vitamin $D$ receptor polymorphisms with autoimmune hepatitis and primary biliary cirrhosis in the Chinese," Journal of Gastroenterology and Hepatology, vol. 20, no. 2, pp. 249-255, 2005.

[29] A. Vogel, C. P. Strassburg, and M. P. Manns, "Genetic association of vitamin D receptor polymorphisms with primary biliary cirrhosis and autoimmune hepatitis," Hepatology, vol. 35, no. 1, pp. 126-131, 2002.

[30] B. Halmos, F. Szalay, T. Cserniczky et al., "Association of primary biliary cirrhosis with vitamin D receptor BsmI genotype polymorphism in a Hungarian population," Digestive Diseases and Sciences, vol. 45, no. 6, pp. 1091-1095, 2000.

[31] European Association for the Study of the Liver, "EASL clinical practice guidelines: management of cholestatic liver diseases," Journal of Hepatology, vol. 51, no. 2, pp. 237-267, 2009.

[32] A. Vogel, C. P. Strassburg, and M. P. Manns, "Genetic association of vitamin D receptor polymorphisms with primary biliary cirrhosis and autoimmune hepatitis," Hepatology, vol. 35, no. 1, pp. 126-131, 2002.

[33] L. Fan, X. Tu, Y. Zhu et al., "Genetic association of vitamin $\mathrm{D}$ receptor polymorphisms with autoimmune hepatitis and primary biliary cirrhosis in the Chinese," Journal of Gastroenterology and Hepatology, vol. 20, no. 2, pp. 249-255, 2005.

[34] B. Halmos, F. Szalay, T. Cserniczky et al., "Association of primary biliary cirrhosis with vitamin D receptor BsmI genotype polymorphism in a Hungarian population," Digestive Diseases and Sciences, vol. 45, no. 6, pp. 1091-1095, 2000.

[35] J. E. Springer, D. E. Cole, L. A. Rubin et al., "Vitamin Dreceptor genotypes as independent genetic predictors of decreased bone mineral density in primary biliary cirrhosis," Gastroenterology, vol. 118, no. 1, pp. 145-151, 2000.

[36] A. Parés, N. Guañabens, and J. Rodés, "Gene polymorphisms as predictors of decreased bone mineral density and osteoporosis in primary biliary cirrhosis," European Journal of Gastroenterology and Hepatology, vol. 17, no. 3, pp. 311-315, 2005.

[37] A. G. Uitterlinden, Y. Fang, J. B. J. van Meurs, H. A. P. Pols, and J. P. T. M. Van Leeuwen, "Genetics and biology of vitamin D receptor polymorphisms," Gene, vol. 338, no. 2, pp. 143-156, 2004.

[38] M. T. Cantorna, W. D. Woodward, C. E. Hayes, and H. F. DeLuca, "1,25-dihydroxyvitamin D3 is a positive regulator for the two anti- encephalitogenic cytokines TGF- $\beta 1$ and IL-4," Journal of Immunology, vol. 160, no. 11, pp. 5314-5319, 1998.

[39] A. Boonstra, F. J. Barrat, C. Crain, V. L. Heath, H. F. J. Savelkoul, and A. O'Garra, " $1 \alpha, 25$-dihydroxyvitamin D3 has a direct effect on naive CD4+ T cells to enhance the development of Th2 cells," Journal of Immunology, vol. 167, no. 9, pp. 49744980, 2001.

[40] J. M. Lemire, D. C. Archer, L. Beck, and H. L. Spiegelberg, "Immunosuppressive actions of 1,25-dihydroxyvitamin D3: preferential inhibition of Th1 functions," Journal of Nutrition, vol. 125, supplement 6, pp. 1704S-1708S, 1995.

[41] M. Willheim, R. Thien, K. Schrattbauer et al., "Regulatory effects of $1 \alpha, 25$-dihydroxyvitamin D3 on the cytokine production of human peripheral blood lymphocytes," Journal of Clinical Endocrinology and Metabolism, vol. 84, no. 10, pp. 3739-3744, 1999.

[42] M. Cippitelli and A. Santoni, "Vitamin D3: a transcriptional modulator of the interferon- $\gamma$ gene," European Journal of Immunology, vol. 28, no. 10, pp. 3017-3030, 1998.

[43] K. Harada and Y. Nakanuma, "Biliary innate immunity and cholangiopathy," Hepatology Research, vol. 37, supplement 3, pp. S430-S437, 2007.

[44] J. M. Ridlon, D. J. Kang, and P. B. Hylemon, "Bile salt biotransformations by human intestinal bacteria," Journal of Lipid Research, vol. 47, no. 2, pp. 241-259, 2006.

[45] M. Makishima, T. T. Lu, W. Xie et al., "Vitamin D receptor as an intestinal bile acid sensor," Science, vol. 296, no. 5571, pp. 1313-1316, 2002. 
[46] S. E. McGarr, J. M. Ridlon, and P. B. Hylemon, "Diet, anaerobic bacterial metabolism, and colon cancer: a review of the literature," Journal of Clinical Gastroenterology, vol. 39, no. 2, pp. 98-109, 2005.

[47] M. Gascon-Barré, C. Demers, A. Mirshahi, S. Néron, S. Zalzal, and A. Nanci, "The normal liver harbors the vitamin D nuclear receptor in nonparenchymal and biliary epithelial cells," Hepatology, vol. 37, no. 5, pp. 1034-1042, 2003. 


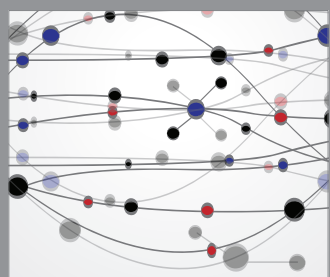

The Scientific World Journal
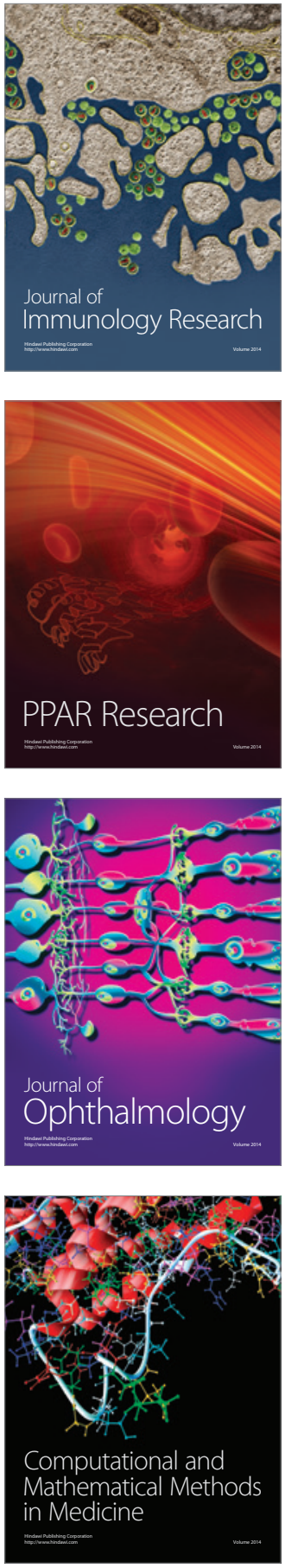

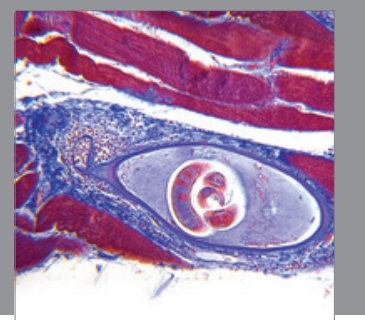

Gastroenterology

Research and Practice
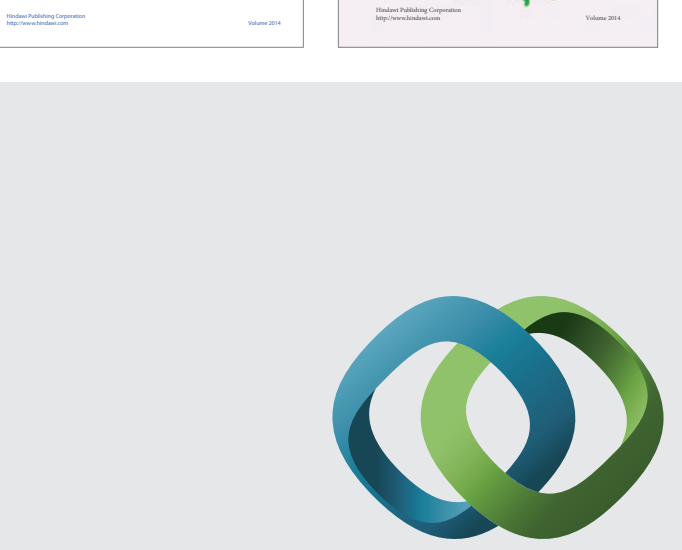

\section{Hindawi}

Submit your manuscripts at

http://www.hindawi.com
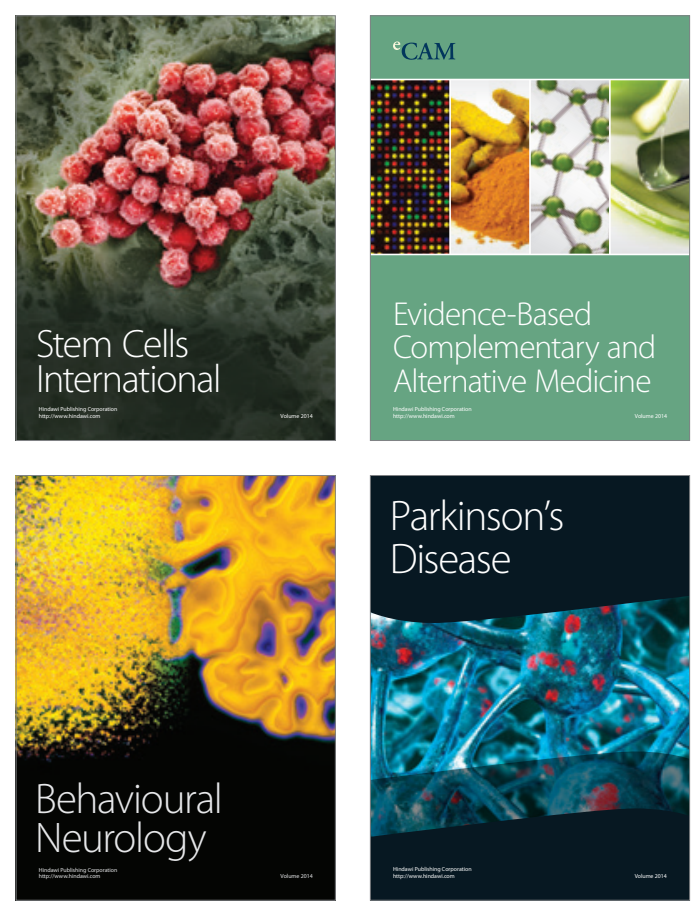

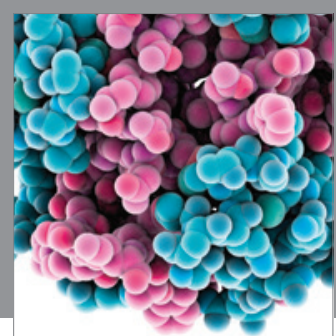

Journal of
Diabetes Research

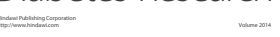

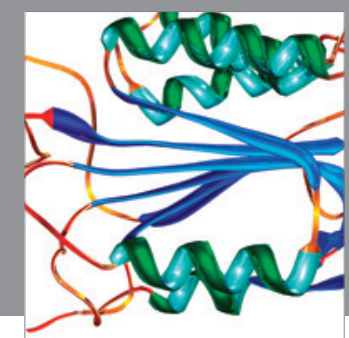

Disease Markers
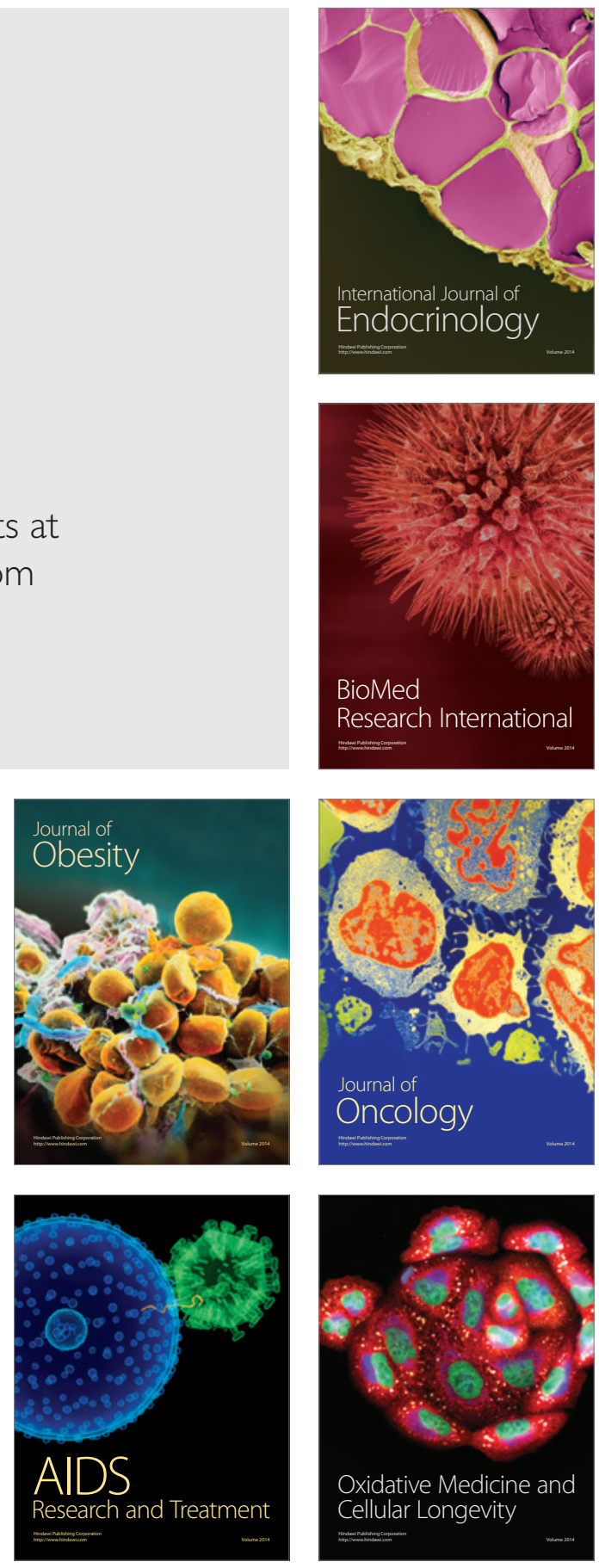